Int. J. Dev. Biol. 49: 363-367 (2005)

doi: 10.1387/ijdb.041942he

\title{
The cap 'n' collar family member NF-E2-related factor 3 (Nrf3) is expressed in mesodermal derivatives of the avian embryo
}

\author{
HEATHER C. ETCHEVERS* \\ INSERM U393, Hopital Necker - Enfants Malades, Paris, France
}

\begin{abstract}
NF-E2-related factor 3 (Nrf3) is a recently identified member of a family of transcription factors homologous to the Drosophila «cap ' $n$ ' collar» or CNC protein. The cnc gene is located immediately $3^{\prime}$ to the Drosophila homeobox gene cluster and has been shown to regulate at least one of those genes, deformed. Likewise, human and mouse CNC homologues are located immediately $3^{\prime}$ to each of the four Hox complexes, although no genetic interactions have yet been demonstrated in vertebrates. Work presented here demonstrates that $\mathbf{N r f 3}$, adjacent to the Hox A cluster, is expressed during early development of the chicken embryo. Expression begins in the presumptive heart myocardium from the time of cardiac tube fusion through the looping process. Nrf3 transcripts then disappear from the heart and are next observed in the myotomal compartment of maturing somites, restricted to the medial portion along the rostrocaudal axis and fading after muscle precursors migrate. Central nervous system expression appears gradually and persists at low levels in ventricular neuroepithelial cells until at least embryonic day 6. Strong expression is observed in the early epiphysis, in the collecting ducts of the developing kidney and in individual cells of the yolk sac, underlying blood islands. This is the first description using in situ hybridization of the expression of a CNC family member and its dynamics through the course of early development.
\end{abstract}

KEY WORDS: cap ' $n$ ' collar, maf, Hox, FGFR2b

\section{Introduction}

In bilaterians, segmental identity along the rostrocaudal axis is conferred through the action of Hox transcription factors, of which the DNA-binding domains have been highly conserved over the course of evolution. Hox genes are organized in chromosomal clusters, where the order of representation in the 3' to 5' direction is reproduced in nested expression domains along the length of the body. The transcription factor cap ' $n$ ' collar is located immediately 3' to the unique Drosophila homeobox gene cluster (Mohler et al., 1991, 1995). Four CNC homologues are found just 3' to each of the four Hox gene clusters of humans and mice: $N F$ E2/p45 (Andrews et al., 1993) near the Hox C complex, Nrf1 (Chan et al., 1996) also known as LCR-F1 (Caterina et al., 1994) near the Hox $B$ complex, Nrf2 (Moi et al., 1994); also known as ECH (Itoh et al., 1995) near the Hox D complex and Nrf3 (Kobayashi et al., 1999; Genbank NM_004289 annotated as NFE2L3), near the Hox $A$ complex.

The CNC factors are basic region-leucine zipper proteins and interact with structurally related factors such as c-fos, small Maf $(F, G, K)$ or Jun proteins, for DNA binding activity. The resultant heterodimers appear to behave as transcriptional activators (reviewed in Veraksa et al., 2000), with the exception of the divergent Bach proteins which show repressor activity (Muto et al., 1998; Oyake et al., 1996). BACH1 and BACH2 map to distinct chromosomes (6q15 and 21q22.1 in humans) and contain additional regulatory domains for protein-protein interactions (Blouin et al., 1998; Ohira et al., 1998; Sasaki et al., 2000). In the absence of a large CNC-type subunit, the small Maf protein partners inhibit promiscuous activation of a consensus binding motif on target DNA sequences, which otherwise can be induced by AP-1-like transcription factors.

The originally identified cap ' $n$ ' collar protein exists as three isoforms through differential splicing. One of these, $\mathrm{CncB}$, is expressed in the pharyngeal endoderm and has been shown to suppress the transcription of Deformed in the Drosophila mandible, thereby maintaining mandibular identity (McGinnis et al., 1998). $c n c A$ and $c n c C$ transcripts are ubiquitously expressed. Deformed is a homeobox-containing transcription factor, located at the 3 '

Abbreviations used in this paper: CNC, cap ' $\mathrm{n}$ ' collar protein; Nrf3, NF-E2related factor 3 . 
end of the homeobox complex. In vertebrates, the Hoxa4, b4, c4 and $d 4$ orthologues of Deformed are expressed within and caudal to the hindbrain in the CNS, in somites and in the esophageal and posterior gut during embryonic life (reviewed in Couly et al., 1996). Expression of cnc family members in vertebrates has been restricted to Northern blot analysis. NF-E2 is only seen in hematopoietic cell lines and tissues such as mouse fetal liver and human adult spleen and bone marrow (Peters et al., 1993). Nrf1 has a reportedly ubiquitous expression (Chan et al., 1993). Nrf2 transcripts are found in mouse red blood cells, kidney and intestine and at lower levels in brain, liver, skeletal muscle and heart (Itoh et al., 1995). Nrf3 is expressed at high levels in the placenta and lower levels in adult human heart, brain, lung, kidney and pancreas (Kobayashi et al., 1999).

In the context of recent data from the Institut d'Embryologie in Nogent-sur-Marne, demonstrating the influence of pharyngeal endoderm and Hox gene expression on the morphogenesis of cephalic neural crest derivatives (Couly et al., 2002; Creuzet et al., 2002), I examined the developing chicken embryo for the possible presence and localization of $C N C$ gene transcripts. One of these, the putative chicken homologue of Nrf3, showed a surprising and dynamic expression pattern in non-cephalic mesodermal derivatives during embryogenesis, notably in the heart, somites, yolk sac and kidney. This pattern was unexpected given the ubiquitous expression described for the CNC genes to date and implies an earlier, more specific role in target gene regulation by Nrf3.

\section{Results}

Nrf3 is first transcribed at detectable levels at HamburgerHamilton stage $(\mathrm{HH}) 10$ in the wall of the fused cardiac tube (not shown). This expression becomes increasingly intense until stage 18 (Figure 1A) and disappears from the myocardium by $\mathrm{HH} 20$ (Figure 1G). Expression appears stronger in the inflow and outflow tracts than in the ventricular wall (Figure 1D).

Somitic expression begins at $\mathrm{HH} 15$ in the rostralmost somites and progresses in a caudal direction (Figure 1C). Nrf3 expression occurs in the median portion of the myotomal compartment along the rostrocaudal axis (Figure $1 \mathrm{~A}, \mathrm{C}, \mathrm{E}$ ). As the myotome differentiates, the strong expression levels are downregulated but not entirely abrogated; migrating hypaxial muscle precursors appear to maintain some Nrf3 expression (Figure 1A and 1F, arrows) and muscle masses in the embryonic day 5 limb continue to faintly express Nrf3 (Figure 1J, arrow). However, expression disappears from the somites by $\mathrm{HH} 20$, which precedes terminal muscle differentiation from the myotome; therefore, it is concluded that not all muscle precursors express Nrf3.

The pharyngeal endoderm only transcribes Nrf3 transiently and at low levels during branchial arch formation. Expression is observed within the endodermal outpocketings separating branchial arches 2-3 and 3-4 at HH18 (Figure 1A, open arrows) and is already absent from this area at $\mathrm{HH} 20$. Uniformly faint levels of $N r f 3$ mRNA are detected throughout the neuroepithelium at both $\mathrm{HH} 18$ and $\mathrm{HH} 20$, with the exception of the strongly expressing epiphyseal placode at these stages (Figure $1 \mathrm{G}, 1 \mathrm{H}$, arrows). The Wolffian ducts do not express $\mathrm{Nrf3}$ at any stage preceding $\mathrm{HH} 18$, when faint expression is observed (Figure 1A, arrowhead).
Between HH26-28, Nrf3 transcription increases dramatically in the mesonephric tubules, resembling collecting ducts (Figure $1 \mathrm{I}-\mathrm{K})$. Not all tubules are positive, but mesonephric glomeruli are essentially negative with the exception of scattered cells (Figure1 L, arrow). Expression is also present in the rostral end of the regressing mesonephric duct (Figure $1 \mathrm{M}$ ).

Concordant with studies showing the importance of CNC type genes in erythroid and platelet differentiation (Andrews et al., 1993; Caterina et al., 1994), Nrf3 is found in a subpopulation of cells within the yolk sac at $\mathrm{HH} 26$ (Figure $1 \mathrm{~N}$ ). These cells are located abutting the blood islands forming in the mesoderm on their endodermal face, a location consistent with hematopoietic precursors that have not yet matured into blood islands (Figure $1 \mathrm{~N}$; Manaia et al., 2000).

\section{Discussion}

Nrf3 is a member of the cap ' $n$ ' collar gene family that has been largely conserved during evolution between the insect and the vertebrate subphyla. In this work, the expression pattern of $\mathrm{Nrf3}$ has been examined at chosen stages of development in the avian embryo. The dynamic and specific activation of Nrf3 in tissues of mesodermal origin shown here is the first demonstration of its potential role in vertebrate embryogenesis.

\section{Conserved Hox partners link Hox and FGF activity}

Nrf2 and Nrf3 have recently been demonstrated to be upregulated through the action of FGF7, or keratinocyte growth factor (KGF), in healing skin wounds (Braun et al., 2002). The embryonic expression pattern of $F G F 7$ significantly overlaps with that of Nrf3 as shown here. Like chicken Nrf3, FGF7 is first detected in the developing heart of the mouse and at higher levels in the atrial than the ventricular end of the cardiac tube, disappearing after further differentiation (Mason et al., 1994). These authors also showed that FGF7 is not detected in epithelial somites but, once the myotome differentiates, is expressed in a rostrocaudal temporal gradient within each somitic myotome and disappears from the somites with the dispersion of the myotome. While this early pattern greatly resembles that of $\mathrm{Nrf3}$ (cf. Figure 1), in contrast, FGF7 continues to be strongly expressed thereafter within all skeletal muscles at levels not equivalent to the low $\mathrm{Nrf3}$ expression visible in muscle masses of the chicken embryo. Other differences include strong localized expression of $F G F 7$ within the telencephalic ventricle, foregut subepithelial mucosa, perichondral mesenchyme and the dermis (Mason et al., 1994), not seen for Nrf3. Finch and colleagues (1995) extended the work of Mason et al. (1994) to compare the expression of FGF7 and its receptor KGFR or FGFR2b (Miki etal., 1992). Examination of the mouse urogenital system revealed strong KGFR expression in the collecting duct epithelia of the kidney, analogous to Nrf3 expression. However, FGFT itself was expressed in the surrounding mesenchyme of the collecting ducts; neither ligand nor receptor was found in the vicinity of the nephrons (Finch et al., 1995). Given these expression domains, it is possible that Nrf3 is a target of FGF7 activity through FGFR2b, but that its transcription is also regulated by other factors.

Other fibroblast growth factors acting through FGFR2b include FGF3, FGF10 and FGF15. These FGFs have been shown to be modulated by the $\mathrm{Pbx}$ transcription factors. Like the vertebrate 

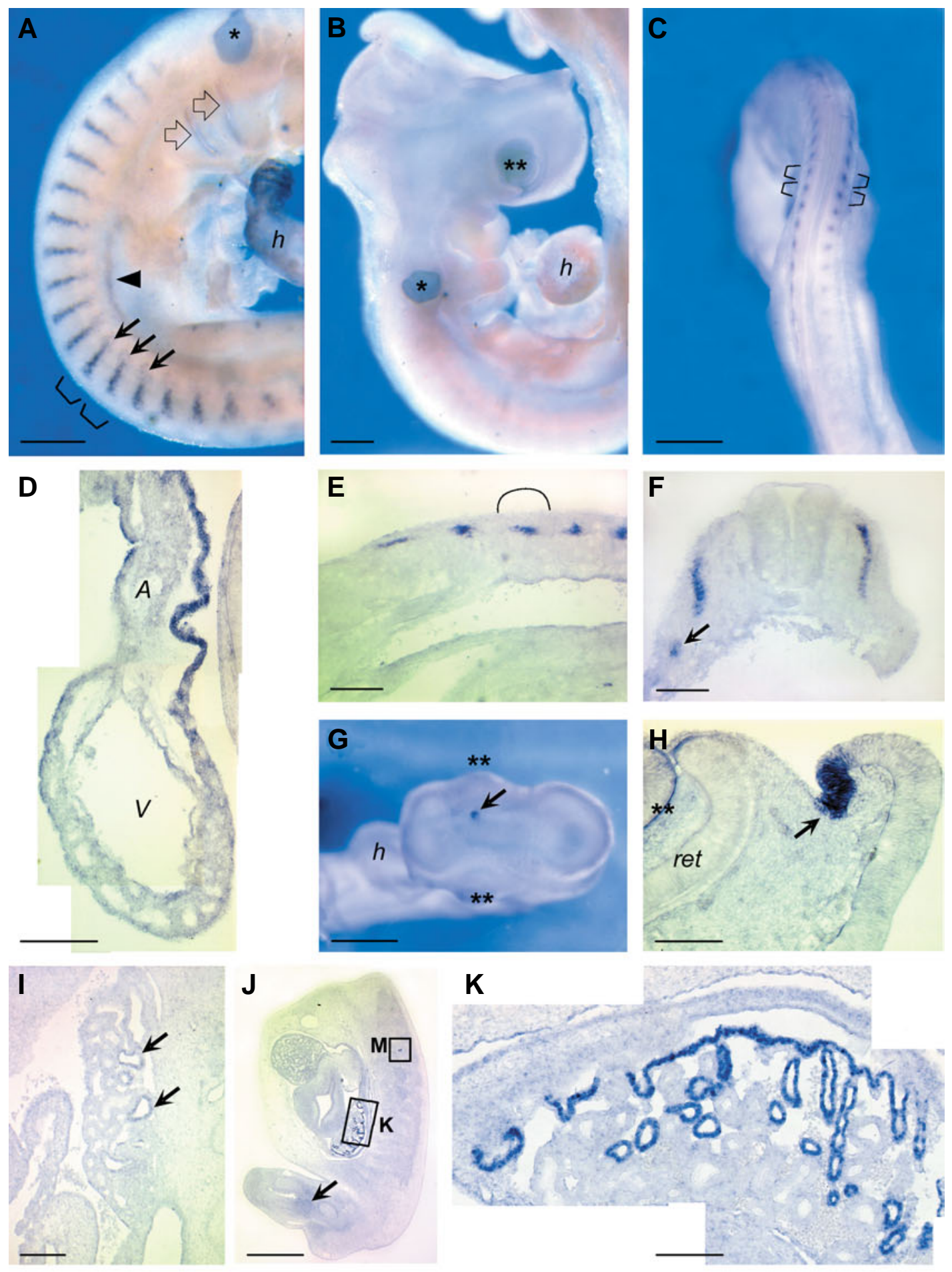

$\mathbf{J}$

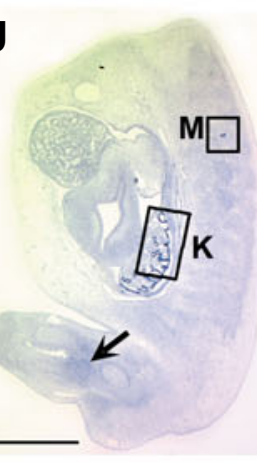

K

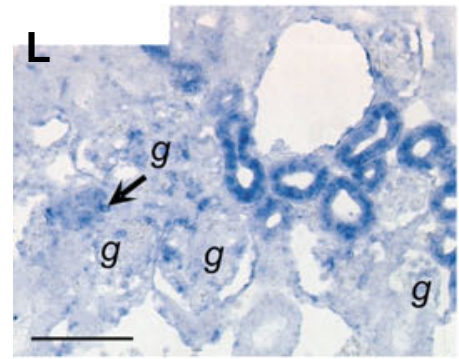

M

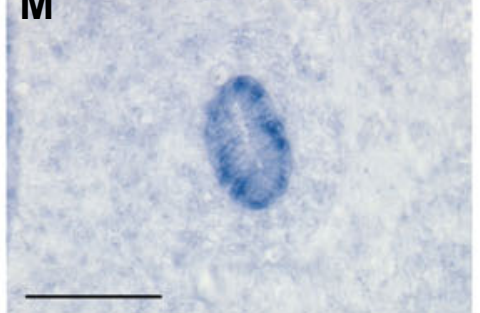

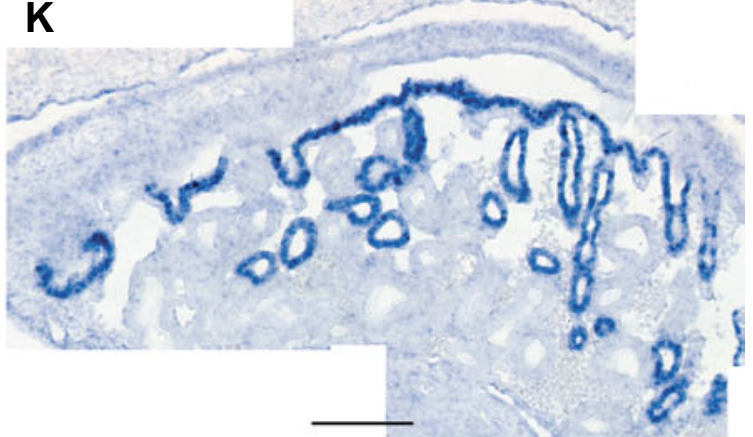

$\mathbf{N}$

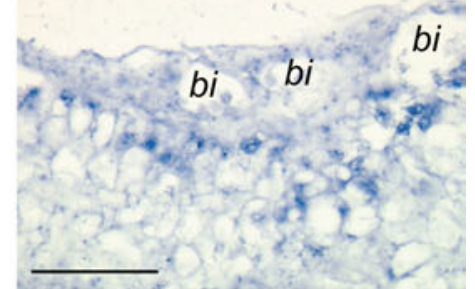

Fig. 1. Expression of Nrf3 in the embryonic chicken. (A) In situ hybridization with an antisense probe against Nrf3 mRNA in a HH18 embryo. Expression is seen in amedialstripe within each somite and in cells migrating ventrally from these stripes (arrows), in the heart (h) and faintly in the Wolffian duct (arrowhead) and the clefts between branchial arches 2/3 and 3/4 lopen arrows). Brackets indicate two examples of somitic boundaries. Asterisk, non-specific signal. (B) Hybridization to a sense probe in a HH18 embryo shows non-specific signal in the optic $\left(^{* *}\right)$ and otic $\left(^{*}\right)$ vesicles. (C) Somitic Nrf3 expression increases gradually as epithelial somites mature; at HH17, caudal somites do not yet have detectable transcripts. Brackets demonstrate somitic boundaries. Rostral to top. (D) Parasagittal section through heart of HH18 embryoshowing more intense Nrf3 expression in the atrial (A) than the ventricular (V) portion. (E) Parasagittal section through somites showing Nrf3 transcripts restricted to the medial third of myotomes along the rostrocaudal axis (bracketed). (F) Myotomal Nrf3 expression at $\mathrm{HH} 18$ is evident in this transverse section at thoracic level. Note transcripts in myoblasts migrating in the hypaxial pathway (arrow). (G) HH17 epiphysis (arrow) expresses Nrf3 locally, seen from top. Double asterisk, eyes; $h$, heart. (H) Epiphyseal Nrf3 expression is strong at HH18 (arrow). The brain had been opened along the dorsal midline for hybridization, dorsal to right. Ret, retina. (I) Nrf3 transcripts are first seen in the developing kidney at HH26 (arrows). (J) Oblique parasagittal section of the body at HH28, rostral to top, facing left. Areas enlarged in $(K, M)$ indicated. Note faint expression in muscle masses of proximal hindlimb, arrow. (K) Nrf3+ collecting ducts of the HH28kidney. (L) Scattered cells, e.g. arrow, express Nrf3 in some glomeruli (g). (M) Rostral end of the receding pronephros also expresses Nrf3. (N) Yolk sac Nrf3 transcripts are seen in cells at the interface between the mesodermal blood islands (bi) and the endoderm. Bars: $A, B, J, 1 \mathrm{~mm} ; C, G, 2 \mathrm{~mm}$; $D, E, F, H, I, K, L, N, 150 \mu m ; M, 100$ $\mu \mathrm{m}$. 
CNC proteins, $\mathrm{Pbx} 1$ is involved in blood formation; human mutations in $P B X 1$ are associated with childhood leukemias (Kamps et al., 1990; Nourse et al., 1990). In Drosophila, the repressive influence of Nrf3's orthologue, cnc, on Deformed is counteracted by the action of the $\mathrm{Pbx}$ orthologue, extradenticle (Veraksa et al., 2000). The feedback binding of Deformed to an element of its own promoter is enhanced by the addition of extradenticle to the reaction (Pinsonneault et al., 1997).

$\mathrm{Pbx} 1$ binds DNA cooperatively with some Hox proteins including those of the first four paralogue groups, targeting and modulating Hox activity (Zakany and Duboule, 1999; Selleri et al., 2001; Waskiewicz etal., 2002). In the zebrafish, Pbx proteins (somewhat redundant in their functions as Hox co-factors) are necessary for the early transcription of FGF3 and FGF8 in a central rhombomere, $r 4$. The FGF signals then exert patterning effects on the flanking rhombomeres $r 3$ and $r 5$. For example, FGF3 from r4, acting through FGFR2b (Ornitz etal., 1996), activates an indirect cascade which results in the differential transcription of Hox genes of paralogue groups 2 and 3 (Waskiewicz et al., 2002).

The Pbx1 protein also directly activates FGF15 transcription, presumably in concert with a Hox protein under normal circumstances (McWhirter et al., 1997). The FGF15 expression domain within the central nervous system is complementary to that of other early-expressed FGFs, including FGF3 and it is also transcribed specifically and transiently within the branchial arch endodermal pouches (McWhirter et al., 1997). Recent evidence implicates FGFR2 and excludes FGFR4 as a possible transducer of the FGF15 signal in the developing mouse brain (Ishibashi and McMahon, 2002), despite an in vitro demonstration that its putative human homologue, FGF19, acts exclusively through FGFR4 (Xie et al., 1999). It would be interesting to compare the FGF15 expression domain with that of members of Hoxparalogue group 4, or to see if FGF15 transcription is repressed by Nrf3 in the branchial arches.

To summarize, FGF signaling through the FGFR2b isoform appears to affect Hox transcriptional activity in a feedback loop, perhaps through altering the balance between Hox repressors of the CNC family such as Nrf3 and Hox activators of the Pbx family. Given its expression pattern, Nrf3 does not appear to be a mediator of hindbrain Hox gene regulation, but it may be involved in determination of mesodermal segments, notably the somites or the embryonic mesonephric collecting ducts. Potential roles in the specification of the pineal gland and in hematopoiesis also remain to be explored.

\section{Materials and Methods}

The chick EST database maintained by the University of Delaware EST project (http://www.chickest.udel.edu/) was screened for the presence of sequences homologous to cnc. One clone, pgp1n.pk002.o10, isolated from a chicken pituitary/hypothalamic/pineal cDNA library, displayed $46 \%$ nucleotide homology to human NRF3 cDNA (Kobayashi et al., 1999) using ALIGN v 2.0 (Myers and Miller, 1989) and was chosen for further analysis. The vector was linearized using Sal I; SP6 RNA polymerase was used to transcribe antisense digoxygenin-labelled RNA probes (Not I and T7 for sense) for in situ hybridizations. Paraffin sections at $7 \mu \mathrm{m}$ or whole embryos were hybridized as described (Henrique et al., 1995; Etchevers et al., 2001); the latter were cut at $10 \mu \mathrm{m}$ on a Leica microtome after embedding in $15 \%$ gelatin $/ 30 \%$ sucrose/PBS that had been cross-linked with $2 \%$ gluteraldehyde. Hamburger-Hamilton stages $7-13,15,17,18$, 24,26 and 28 were examined.

\section{Acknowledgements}

H.C.E. is an Avenir fellow and staff researcher of the French Institut National de la Santé et de la Recherche Médicale and was supported by the Sturge-Weber Foundation during part of this work. She expresses her warm appreciation to her mentors, Professors Nicole Le Douarin and Gérard Couly and to Dr. Tania Attié-Bitach for her constructive criticism. This paper is dedicated to the fond memory of Dr. Patrizia CameronCurry, a staffscientist of the Institut d'Embryologie Cellulaire et Moléculaire du CNRS et du Collège de France.

Note added in press:

Chenais et al. (2004) have recently demonstrated that Nrf3 and its small Maf partner, MafG, are a transcriptional activator in human placental chorionic villus cytotrophoblasts.

\section{References}

ANDREWS, N.C., ERDJUMENT-BROMAGE, H., DAVIDSON, M.B., TEMPST, P. and ORKIN, S.H. (1993). Erythroid transcription factor NF-E2 is a haematopoieticspecific basic-leucine zipper protein. Nature 362, 722-728.

BEL-VIALAR, S., ITASAKI, N. and KRUMLAUF, R. (2002). Initiating Hox gene expression: in the early chick neural tube differential sensitivity to FGF and RA signaling subdivides the HoxB genes in two distinct groups. Development 129, 5103-5115.

BLOUIN, J.L., DURIAUXSAIL, G., GUIPPONI, M., ROSSIER, C., PAPPASAVAS, M.P. and ANTONARAKIS, S.E. (1998). Isolation of the human BACH1 transcription regulator gene, which maps to chromosome 21q22.1. Hum. Genet. 102, 282-288.

BRAUN, S., HANSELMANN, C., GASSMANN, M.G., AUF DEM KELLER, U., BORN-BERCLAZ, C., CHAN, K., KAN, Y.W. and WERNER, S. (2002). Nrf2 transcription factor, a novel target of keratinocyte growth factor action which regulates gene expression and inflammation in the healing skin wound. Mol. Cell. Biol. 22, 5492-5505.

CATERINA, J.J., DONZE, D., SUN, C.W., CIAVATTA, D.J. and TOWNES, T.M. (1994). Cloning and functional characterization of LCR-F1: a bZIP transcription factor that activates erythroid-specific, human globin gene expression. Nucleic Acids Res. 22, 2383-2391.

CHAN, J. Y., HAN, X. L. and KAN, Y. W. (1993). Cloning of Nrf1, an NF-E2-related transcription factor, by genetic selection in yeast. Proc. Natt. Acad. Sci. USA90, $11371-5$

CHAN, K., LU, R., CHANG, J.C. and KAN, Y.W. (1996). NRF2, a member of the NFE2 family of transcription factors, is not essential for murine erythropoiesis, growth and development. Proc. Natl. Acad. Sci. USA 96, 13943-13948.

CHENAIS, B., DERJUGA, A., MASSRIEH, W., RED-HORSE, K., BELLINGARD, V., FISHER, S.J. AND BLANK, V. (2004). Functional and placental expression analysis of the human NRF3 transcription factor. Mol Endocrinol. dori10.1210/ me/2003-0379.

COULY, G., GRAPIN-BOTTON, A., COLTEY, P. and LE DOUARIN, N. M. (1996). The regeneration of the cephalic neural crest, a problem revisited: the regenerating cells originate from the contralateral or from the anterior and posterior neural fold. Development 122, 3393-407.

COULY, G., CREUZET, S., BENNACEUR, S., VINCENT, C. and LE DOUARIN, N.M. (2002). Interactions between Hox-negative cephalic neural crest cells and the foregut endoderm in patterning the facial skeleton in the vertebrate head. Development 129, 1061-1073.

CREUZET, S., COULY, G., VINCENT, C. and LE DOUARIN, N.M. (2002). Negative effect of Hox gene expression on the development of the neural crest-derived facial skeleton. Development 129, 4301-4313.

DEBACKER, C., CATALA, M. and LABASTIE, M.C. (1999). Embryonic expression of the human GATA-3 gene. Mech Dev. 85, 183-7.

ETCHEVERS, H.C., VINCENT, C. and LE DOUARIN, N.M. and COULY, G.F. (2001). The cephalic neural crest provides pericytes and smooth muscle cells to all blood vessels of the face and forebrain. Development 128, 1059-1068.

FINCH, P.W., CUNHA, G.R., RUBIN, J.S., WONG, J. and RON, D. (1995). Pattern of keratinocyte growth factor and keratinocyte growth factor receptor expression during mouse fetal development suggests a role in mediating morphogenetic mesenchymal-epithelial interactions. Dev. Dyn. 203, 223-240. 
HENRIQUE, D., ADAM, J., MYAT, A., CHITNIS, A., LEWIS, J. and ISH-HOROWICZ, D. (1995). Expression of a Delta homologue in prospective neurons in the chick. Nature 375, 787-790.

ISHIBASHI, M. and MCMAHON, A.P. (2002). A sonic hedgehog-dependent signaling relay regulates growth of diencephalic and mesencephalic primordia in the early mouse embryo. Development 129, 4807-4819.

ITOH, K., IGARASHI, K., HAYASHI, N., NISHIZAWA, M. and YAMAMOTO, M. (1995). Cloning and characterization of a novel erythroid cell-derived CNC family transcription factor heterodimerizing with the small Maf family proteins. Mol. Cell. Biol. 15, 4184-4193.

KAMPS, M.P., MURRE, C., SUN, X.H. and BALTIMORE, D. (1990). A new homeobox gene contributes the DNA binding domain of the $t(1 ; 19)$ translocation protein in pre-B ALL. Ce//60, 547-555.

KOBAYASHI, A., ITO, E., TOKI, T., KOGAME, K., TAKAHASHI, S., IGARASHI, K., HAYASHI, N. and YAMAMOTO, M. (1999). Molecular cloning and functional characterization of a new Cap'n' collar family transcription factor Nrf3. J. Biol. Chem. 274, 6443-6452.

MANAIA, A., LEMARCHANDEL, V., KLAINE, M., MAX-AUDIT, I., ROMEO, P., DIETERLEN-LIEVRE, F. and GODIN, I. (2000). Lmo2 and GATA-3 associated expression in intraembryonic hemogenic sites. Development 127, 643-53.

MASON, I.J., FULLER-PACE, F., SMITH, R. and DICKSON, C. (1994). FGF-7 (keratinocyte growth factor) expression during mouse development suggests roles in myogenesis, forebrain regionalisation and epithelial-mesenchymal interactions. Mech. Dev. 45, 15-30.

MCGINNIS, N., RAGNHILDSTVEIT, E., VERAKSA, A. and MCGINNIS, W. (1998). A cap ' $n$ ' collar protein isoform contains a selective Hox repressor function. Development 125, 4553-4564.

MCWHIRTER, J.R., GOULDING, M., WEINER, J.A., CHUN, J. and MURRE, C. (1997). A novel fibroblast growth factor gene expressed in the developing nervous system is a downstream target of the chimeric homeodomain oncoprotein E2A-Pbx1. Development 124, 3221-3232.

MIKI, T., BOTTARO, D.P., FLEMING, T.P., SMITH, C.L., BURGESS, W.H., CHAN, A.M. and AARONSON, S.A. (1992). Determination of ligand-binding specificity by alternative splicing: two distinct growth factor receptors encoded by a single gene. Proc. Natl. Acad. Sci. USA 89, 246-250.

MOHLER, J., MAHAFFEY, J.W., DEUTSCH, E. and VANI, K. (1995). Control of Drosophila head segment identity by the bZIP homeotic gene cnc. Development 121, 237-247.

MOHLER, J., VANI, K., LEUNG, S. and EPSTEIN, A. (1991). Segmentally restricted, cephalic expression of a leucine zipper gene during Drosophila embryogenesis. Mech. Dev. 34, 3-9.

MOI, P., CHAN, K., ASUNIS, I., CAO, A. and KAN, Y.W. (1994). Isolation of NF-E2related factor 2 (Nrf2), a NF-E2-like basic leucine zipper transcriptional activator that binds to the tandem NF-E2/AP1 repeat of the beta-globin locus control region. Proc. Natl. Acad. Sci. USA 91, 9926-9930.

MUTO, A., HOSHINO, H., MADISEN, L., YANAI, N., OBINATA, M., KARASUYAMA, H., HAYASHI, N., NAKAUCHI, H., YAMAMOTO, M., GROUDINE, M. and
IGARASHI, K. (1998). Identification of Bach2 as a B-cell-specific partner for small maf proteins that negatively regulate the immunoglobulin heavy chain gene 3' enhancer. EMBO J. 17, 5734-5743.

MYERS, E. and MILLER, W. (1988) Optimal alignments in linear space. CABIOS 4, 11-17.

NOURSE, J., MELLENTIN, J.D., GALILI, N., WILKINSON, J., STANBRIDGE, E., SMITH, S.D. and CLEARY, M.L. (1990). Chromosomal translocation $t(1 ; 19)$ results in synthesis of a homeobox fusion mRNA that codes for a potential chimeric transcription factor. Ce//60, 535-545.

OHIRA, M., SEKI, N., NAGASE, T., ISHIKAWA, K., NOMURA, N. and OHARA, O. (1998). Characterization of a human homolog $(B A C H 1)$ of the mouse Bach1 gene encoding a BTB-basic leucine zipper transcription factor and its mapping to chromosome 21q22.1. Genomics 47, 300-306

ORNITZ, D.M., XU, J., COLVIN, J.S., MCEWEN, D.G., MACARTHUR, C.A., COULIER, F., GAO, G. and GOLDFARB, M. (1996). Receptor specificity of the fibroblast growth factor family. J. Biol. Chem. 271, $15292-15297$.

OYAKE, T., ITOH, K., MOTOHASHI, H., HAYASHI, N., HOSHINO, H., NISHIZAWA, M., YAMAMOTO, M. and IGARASHI, K. (1996). Bach proteins belong to a nove family of BTB-basic leucine zipper transcription factors that interact with MafK and regulate transcription through the NF-E2 site. Mol. Cell. Biol. 16, 6083 6095.

PETERS, L.L. ANDREWS, N.C., EICHER, E.M., DAVIDSON, M.B., ORKIN, S.H. and'LUX, S. E. (1993). Mouse microcytic anaemia caused by a defect in the gene encoding the globin enhancer-binding protein NF-E2. Nature362, 768-70.

PINSONNEAULT, J., FLORENCE, B., VAESSIN, H. and MCGINNIS, W. (1997). A model for extradenticle function as a switch that changes HOX proteins from repressors to activators. EMBO J. 16, 2032-2042.

SASAKI, S., ITO, E., TOKI, T., MAEKAWA, T., KANEZAKI, R., UMENAI, T., MUTO, A., NAGAI, H., KINOSHITA, T. and YAMAMOTO, M. (2000). Cloning and expression of human $B$ cell-specific transcription factor $\mathrm{BACH} 2$ mapped to chromosome 6q15. Oncogene 19, 3739-3749.

SELLERI, L., DEPEW, M.J., JACOBS, Y., CHANDA, S.K., TSANG, K.Y., CHEAH K.S., RUBENSTEIN, J.L., O'GORMAN, S. and CLEARY, M.L. (2001). Requirement for $\mathrm{Pbx} 1$ in skeletal patterning and programming chondrocyte proliferation and differentiation. Development 128, 3543-3557.

VERAKSA, A., MCGINNIS, N., LI, X., MOHLER, J. and MCGINNIS, W. (2000). Cap ' $n$ ' collar B cooperates with a small Maf subunit to specify pharyngeal development and suppress deformed homeotic function in the Drosophila head. Development 127, 4023-4037.

WASKIEWICZ, A.J., RIKHOF, H.A. and MOENS, C.B. (2002). Eliminating zebrafish pbx proteins reveals a hindbrain ground state. Dev. Cell. 3, 723-733.

XIE, M.H., hOlCOMB, I., DEUEl, B., DOWD, P., HUANG, A., VAGTS, A. FOSTER, J., LIANG, J., BRUSH, J. and GU, Q. (1999). FGF-19, a nove fibroblast growth factor with unique specificity for FGFR4. Cytokine 11, 729 735.

ZAKANY, J. and DUBOULE, D. (1999). Hox genes in digit development and evolution. Cell Tissue Res. 296, 19-25. 